\title{
Nonlinear control of grid-connected wind energy conversion system without mechanical variables measurements
}

\author{
Karim Noussi $^{1}$, Abdelmajid Abouloifa ${ }^{2}$, Hanane Katir $^{3}$, Ibtissam Lachkar ${ }^{4}$, Fouad Giri ${ }^{5}$ \\ ${ }^{1,2,3}$ TI Lab, Faculty of Sciences Ben M'sick, University Hassan II, Casablanca, Morocco. \\ ${ }^{4}$ ESE Lab, ENSEM of Casablanca, University Hassan II, Casablanca, Morocco. \\ ${ }^{5}$ NORMANDIE UNIV, UNICAEN, ENSICAEN, LAC, 14000 Caen, France.
}

\section{Article Info}

Article history:

Received Aug 28, 2020

Revised Mar 31, 2021

Accepted Apr 17, 2021

\section{Keywords:}

AC/DC/AC converter Doubly fed induction generator

High gain observer

Sliding mode control

Wind energy conversion

system

\begin{abstract}
This article addresses the problem of controlling an overall wind energy conversion system (WECS) formed by a wind turbine connected to the grid via a doubly fed induction generator (DFIG) and an AC/DC/AC converter. The main control objectives are fourfold: (i) designing an output feedback speed controller that makes the DFIG rotate at the optimal value delivered by the MPPT strategy, (ii) controlling the stator reactive power so as to be null, (iii) guaranteeing the DC-link voltage in the grid side converter to be at a given constant value, (iv) ensuring a unitary power factor. A high gain observer is synthesized, in order to provide estimated values of the mechanical variables. To achieve the control objectives, a sliding mode controller involving the mechanical observer is designed. The performance of the system configuration based on the 2MW-DFIG with the proposed controller is evaluated by a numerical simulation under a realistic wind profile using MATLAB/SIMULINK/SimPowerSystems environment.
\end{abstract}

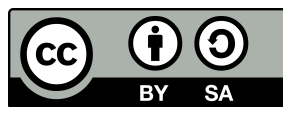

Corresponding Author:

Karim Noussi

TI Lab, Faculty of Sciences Ben M'sick, University Hassan II of Casablanca, BP 7955 Casablanca, Morocco.

Email: karim.noussi2@gmail.com

\section{INTRODUCTION}

Energy is a major factor in the growth of industrial production. Renewable energies mainly wind and solar are becoming the most supported solutions; as a result of less abundant fossil fuels, greenhouse gas effect and high population growth [1]. On the other side, wind power is a globally available solution unlike solar power due to its limitation to specific regions. Wind energy conversion systems are the fastest expanding technology and the key components to clean and save energy [2]. Among all variable-speed wind turbine designs, two commercial leading technologies are introduced in extensive scale; wind turbine based DFIG and synchronous generator (SG). Indeed, DFIG technology has overtaken other ones because of its cost, robustness, reliability and small power converters requirements [3], [4].

In this work, we are concerned with the control of the whole wind energy conversion system formed by a wind turbine connected to the grid via a DFIG, a back-to-back converter and three phase RL filter. The back-to-back converter includes two identical two-level voltage source converters; a rotor side converter (RSC) and a grid side converter (GSC), linked by a capacitor. The converter consists of six insulated gate bipolar transistors (IGBT) with anti-parallel diodes to allow the flow of current in both directions [5], [6]. To get full 
benefits from the DFIG machine, different control techniques are employed for the synthesis of the DFIG wind turbine system such as the field-oriented control used to decouple and regulate the torque and the stator reactive power with classical PI-regulator, proposed in [7], [8]. DTC/DPC strategies are employed to control the WECS powers in [9], a fuzzy logic controller is designed for power capture optimization in [10]. To optimize power production of DFIG, a host of research works controlled the discussed system using nonlinear control strategies such as the backstepping approach designed in [11], feedback linearization technique presented in [12], and flatness-based approach used in [13]. However, in these works, the mechanical torque and the generator speed are considered as measurable variables which is inappropriate in industrial solutions for electric drive systems as long as one seeks to eliminate the mechanical sensors because they increase the maintenance costs and reduce the system reliability, thus affecting the overall wind turbine system stability. In [14], authors proposed a sensorless backstepping control technique for the DFIG. Nevertheless, only the generator speed is estimated whereas the mechanical torque is assumed to be measurable. In this paper a high gain observer is synthesized, in order to provide online estimation of the mechanical torque and the generator speed, only the electrical variables are assumed to be as measurable quantities.

This article presents a sliding mode controller design in order to control the power converters associated with the generator which are the key components to handle the energy between the wind turbine and the electrical grid. The RSC aims at regulating the generator speed to track the optimal reference provided by the MPPT block, the speed controller is designed based on the mechanical observer, and regulate the stator reactive power so as to be null. The GSC aims at guaranteeing that the DC-link is maintained at a given constant value and ensuring a unitary power factor by keeping the grid side reactive power at zero.

The remaining sections of the paper are organized as follows: In Section 2, the whole wind energy conversion system mathematical model is presented, followed by the sliding mode controller design described in details for the proposed system in Section 3. The high gain observer is introduced in Section 4. The simulation results are discussed in Section 5. Lastly, conclusions and future scopes are drawn in Section 6.

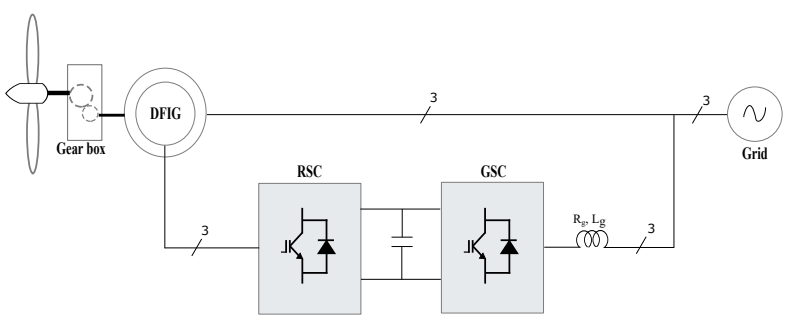

Figure 1. Wind energy conversion system topology

\section{SYSTEM MODELLING}

The complete system scheme is depicted in Figure 1. According to [5], [15], the mathematical model in state space form in d-q reference frame of the DFIG connected to the back-to-back converter can be summarized by the following differential equations:

$$
\begin{gathered}
\dot{x}_{1}=\frac{\mu}{J} x_{2}-\frac{f_{v}}{J} x_{1}-\frac{1}{J} C_{g} \\
\dot{x}_{2}=\frac{1}{\sigma L_{r}}\left(\frac{x_{4}}{2} u_{q}-R_{r} x_{2}-\omega_{r} \sigma L_{r} x_{3}-\omega_{r} \frac{L_{m} V_{s}}{\omega_{s} L_{s}}\right) \\
\dot{x}_{3}=\frac{1}{\sigma L_{r}}\left(\frac{x_{4}}{2} u_{d}-R_{r} x_{3}+\omega_{r} \sigma L_{r} x_{2}\right) \\
\dot{x}_{4}=\frac{1}{C_{d c}}\left(-\frac{3}{2} \frac{V_{s}}{x_{4}} x_{5}+i_{r d c}\right) \\
\dot{x}_{5}=\frac{1}{L_{g}}\left(\frac{x_{4}}{2} v_{q}-R_{g} x_{5}-V_{s}-\omega_{s} L_{g} x_{6}\right)
\end{gathered}
$$




$$
\dot{x}_{6}=\frac{1}{L_{g}}\left(\frac{x_{4}}{2} v_{d}-R_{g} x_{6}+\omega_{s} L_{g} x_{5}\right)
$$

where $\left[x_{1}, x_{2}, x_{3}, x_{4}, x_{5}, x_{6}\right]=\left[\Omega_{m}, i_{r q}, i_{r d}, v_{d c}, i_{g q}, i_{g d}\right]$ denotes the state vector. $u_{d}, u_{q}, v_{d}$ and $v_{q}$ are the back-to-back converter control inputs in d-q reference frame. $\Omega_{m}, C_{g}, p, J$ and $f_{v}$ are the DFIG mechanical rotational speed, mechanical torque, the number of pole pairs, the rotor inertia and the friction coefficient, respectively. (with $\Omega_{t}=\Omega_{m} / N$ and $C_{t}=C_{g} . N, N$ is the gear box gain. Since the shaft rotor coupling involves a gearbox). $\omega_{s}, \omega_{m}$ and $\omega_{r}$ denote the stator flux synchronous speed, the angular rotor speed and the rotor angular frequency, respectively, (with $\omega_{r}=\omega_{s}-\omega_{m}$ ). $i_{r d}, i_{g d}$ are the rotor and filter direct current components. $i_{r q}, i_{g q}$ are the rotor and filter quadrature current components. $V_{s}$ is the magnetizing amplitude. $R_{s}, R_{r}$ and $R_{g}$ designate the stator, rotor and filter resistor, respectively. $L_{s}, L_{r}, L_{m}$ and $L_{g}$ indicate the stator, rotor, mutual and filter inductance, respectively. $C_{d c}$ is the DC-link capacitor, $i_{r d c}$ represents the current flowing through the RSC. $\mu=\left(-3 p L_{m} V_{s}\right) /\left(2 L_{s} \omega_{s}\right)$ designates the electromagnetic torque constant and $\sigma=1-L_{m}^{2} /\left(L_{s} L_{r}\right)$ is Blondel's dispersion coefficient.

\section{CONTROLLER DESIGN}

\subsection{Rotor side converter controller}

The RSC employs the sliding mode control technique to transfer the available electrical power from the DFIG stator to the utility grid. The electrical power is generated via the mechanical power produced by the wind turbine rotor. The controller involves two control loops: the first one is the speed control loop that aims at regulating the generator speed to track the optimal reference provided by the MPPT block. The second one is the stator reactive power control loop which is intended to control the stator reactive power so as to be null [16]-[18].

\subsubsection{Generator speed control loop:}

Define the following second order sliding mode surface [19], [20]:

$$
S_{\omega}\left(x, C_{g}\right)=\dot{e}_{1}+\delta_{1} e_{1}
$$

where $e_{1}=x_{1}-x_{1}^{*}$ denotes the tracking error between the generator speed and its optimal value, and $\delta_{1}$ is the positive parameter design.

It follows from (1) that the error $e_{1}$ undergoes the following equation:

$$
\dot{e}_{1}=-\frac{f_{v}}{J} x_{1}+\frac{\mu}{J} x_{2}-\frac{1}{J} C_{g}-\dot{x}_{1}^{*}
$$

Based on (1), (2), (7) and (8), the time derivative of the sliding surface is given by:

$$
\dot{S}_{\omega}=z_{1}\left(x, C_{g}, t\right)+\frac{\mu x_{4}}{2 \sigma J L_{r}} u_{q}
$$

where,

$$
\begin{aligned}
& z_{1}\left(x, C_{g}, t\right)=\left(\delta_{1}-\frac{f_{v}}{J}\right)\left(-\frac{f_{v}}{J} x_{1}+\frac{\mu}{J} x_{2}-\frac{1}{J} C_{g}\right)-\frac{\mu}{\sigma J L_{r}}\left(R_{r} x_{2}+\omega_{r} \sigma L_{r} x_{3}+\omega_{r} \frac{L_{m} V_{s}}{\omega_{s} L_{s}}\right) \\
& -\frac{1}{J} \dot{C}_{g}-\ddot{x}_{1}^{*}-\delta_{1} \dot{x}_{1}^{*}
\end{aligned}
$$

By setting the dynamics of the sliding surface to zero, one can obtain the equivalent control law which ensures the attractiveness and invariance of the sliding surface $S_{\omega}$ :

$$
u_{q, e q}=-\frac{2 \sigma J L_{r}}{\mu x_{4}} z_{1}\left(x, C_{g}, t\right)
$$

Let us consider the positive Lyapunov function candidate:

$$
W_{1}=\frac{1}{2} S_{\omega}^{2}
$$


Differentiating (12), yields:

$$
\dot{W}_{1}=S_{\omega}\left(z_{1}\left(x, C_{g}, t\right)+\frac{\mu x_{4}}{2 \sigma J L_{r}} u_{q}\right)
$$

By substituting (11) in (13), one gets:

$$
\dot{W}_{1}=\frac{\mu x_{4}}{2 \sigma J L_{r}} S_{\omega} u_{q, n}
$$

The following discrete control law will be chosen to guarantee the dynamics of the candidate Lyapunov function to be negative:

$$
u_{q, n}=-\frac{2 \sigma J L_{r}}{\mu x_{4}} k_{\omega} \operatorname{sgn}\left(S_{\omega}\right)
$$

where $k_{\omega}$ is the controller parameter to be designed.

Then, the generator speed global control law is given by:

$$
u_{q}=-\frac{2 \sigma J L_{r}}{\mu x_{4}}\left(z_{1}\left(x, C_{g}, t\right)+k_{\omega} \operatorname{sgn}\left(S_{\omega}\right)\right)
$$

\subsubsection{Stator reactive power control loop:}

To design a controller for the stator reactive power exchanged with the grid, the sliding surface is defined as follows:

$$
S_{Q}(x)=e_{2}=Q_{s}-Q_{s}^{*}
$$

where the reactive power equation is given by [5]

$$
Q_{s}=-\frac{3}{2} \frac{L_{m} V_{s}}{L_{s}}\left(x_{3}-\frac{V_{s}}{\omega_{s} L_{m}}\right)
$$

Using equations (3), (17) and (18), the sliding surface $S_{Q}$ undergoes the differential equation:

$$
\dot{S}_{Q}=-\frac{3}{2} \frac{L_{m} V_{s}}{\sigma L_{s} L_{r}}\left(\frac{x_{4}}{2} u_{d}-R_{r} x_{3}+\omega_{r} \sigma L_{r} x_{2}\right)-\dot{Q}_{s}^{*}
$$

with $\dot{S}_{Q}=0$, the equivalent control law $u_{d, e q}$ can be expressed by:

$$
u_{d, e q}=\frac{2}{x_{4}}\left(R_{r} x_{3}-\omega_{r} \sigma L_{r} x_{2}\right)-\frac{4}{3} \frac{\sigma L_{s} L_{r}}{L_{m} V_{s} x_{4}} \dot{Q}_{s}^{*}
$$

Considering the following candidate Lyapunov function:

$$
W_{2}=\frac{1}{2} S_{Q}^{2} \Rightarrow \dot{W}_{2}=S_{Q} \dot{S}_{Q}
$$

It follows from (19) that:

$$
\dot{W}_{2}=S_{Q}\left(-\frac{3}{2} \frac{L_{m} V_{s}}{\sigma L_{s} L_{r}}\left(\frac{x_{4}}{2} u_{d}-R_{r} x_{3}+\omega_{r} \sigma L_{r} x_{2}\right)-\dot{Q}_{s}^{*}\right)
$$

Replacing (20) in (22), one gets:

$$
\dot{W}_{2}=-\frac{3}{4} \frac{L_{m} V_{s} x_{4}}{\sigma L_{s} L_{r}} S_{Q} u_{d, n}
$$

The following discrete control law will be constructed which ensures the negativity of the derivative of the candidate Lyapunov function $W_{2}$ :

$$
u_{d, n}=\frac{4}{3} \frac{\sigma L_{s} L_{r}}{L_{m} V_{s} x_{4}} k_{Q} \operatorname{sgn}\left(S_{Q}\right)
$$

where $k_{Q}$ is the controller parameter to be designed.

Consequently, the final control law for the stator reactive power is given by:

$$
u_{d}=\frac{2}{x_{4}}\left(R_{r} x_{3}-\omega_{r} \sigma L_{r} x_{2}\right)+\frac{4}{3} \frac{\sigma L_{s} L_{r}}{L_{m} V_{s} x_{4}}\left(k_{Q} \operatorname{sgn}\left(S_{Q}\right)-\dot{Q}_{s}^{*}\right)
$$




\subsection{Grid side converter controller}

The GSC also employs the sliding mode control technique, in order to exchange with the grid only the active power extracted or injected by the RSC from the rotor, which is indirectly controlled through the DC-link regulator [21], [22]. To this end, the GSC controller involves two control loops. DC-link and d-axis current control loops. On one hand, the DC-link control loop aims at regulating the DC-link voltage at a given constant value which is equal to the converter nominal voltage to avoid the damage of the RSC. On the other hand, the d-axis control loop is used to force the reactive power to be null, thus ensuring a unitary power factor by maintaining the direct current at its reference value that is equal to zero.

\subsubsection{DC-link voltage control loop:}

Let us define the DC-link voltage tracking error between the actual voltage and its reference as:

$$
e_{3}=x_{4}-x_{4}^{*}
$$

Using (4), the dynamics of the error $e_{3}$ are written as:

$$
\dot{e}_{3}=\dot{x}_{4}-\dot{x}_{4}^{*}=\frac{1}{C_{d c}}\left(-\frac{3}{2} \frac{V_{s}}{x_{4}} x_{5}+i_{r d c}\right)-\dot{x}_{4}^{*}
$$

Taking into account the tracking error (26) and its dynamics (27), the considered sliding surface is defined:

$$
S_{v}(x)=\dot{e}_{3}+\delta_{2} e_{3}
$$

where $\delta_{2}$ is the positive parameter design.

It follows from (5), (27) and (28) that the time derivative of the sliding surface $S_{v}$ has the next form:

$$
\dot{S}_{v}=z_{2}(x, t)-\frac{3}{4} \frac{V_{s}}{L_{g} C_{d c}} v_{q}
$$

where

$$
\begin{aligned}
z_{2}(x, t)=\frac{1}{C_{d c}} & \left(\dot{i}_{r d c}+\frac{3}{2} \frac{V_{s}}{x_{4} L_{g}}\left(R_{g} x_{5}+V_{s}+\omega_{s} L_{g} x_{6}\right)\right)+ \\
& \left(\frac{\delta_{2}}{C_{d c}}+\frac{3}{2} \frac{V_{s}}{C_{d c}^{2} L_{g} x_{4}^{2}}\right)\left(i_{r d c}-\frac{3}{2} \frac{V_{s}}{x_{4}} x_{5}\right)-\ddot{x}_{4}^{*}-\delta_{2} \dot{x}_{4}^{*}
\end{aligned}
$$

In order to find out the equivalent control law that ensures the attractiveness and invariance of the sliding surface, we set the dynamics of the sliding surface $S_{v}$ to zero.

$$
v_{q, e q}=\frac{4}{3} \frac{L_{g} C_{d c}}{V_{s}} z_{2}(x, t)
$$

The Lyapunov function candidate can be defined as $W_{3}=\frac{1}{2} S_{v}^{2}$ and in order to make its derivative negative, the following discrete control law will be constructed:

$$
v_{q, n}=\frac{4}{3} \frac{L_{g} C_{d c}}{V_{s}} k_{v} \operatorname{sgn}\left(S_{v}\right)
$$

where $k_{v}$ is the controller parameter.

In view of (31) and (32), the global control law for the DC-link voltage is given by:

$$
v_{q}=\frac{4}{3} \frac{L_{g} C_{d c}}{V_{s}}\left(z_{2}(x, t)+k_{v} \operatorname{sgn}\left(S_{v}\right)\right)
$$




\subsubsection{D-axis current control loop:}

To control the grid side d-axis current $x_{6}$, we proceed in the same way as for the earlier control loops. Based on the alignment discussed in [5], one can calculate the reference of the d-axis current such as $x_{6}^{*}=\left(2 Q_{g}^{*}\right) /\left(3 V_{s}\right)$, where $Q_{g}^{*}$ is the grid side reactive power reference.

Let us consider the sliding surface $S_{i d}(x)=e_{4}=x_{6}-x_{6}^{*}$. Using (6) the derivative of the sliding surface with respect to time is given by:

$$
\dot{S}_{i d}=\dot{e}_{4}=\frac{1}{L_{g}}\left(\frac{x_{4}}{2} v_{d}-R_{g} x_{6}+\omega_{s} L_{g} x_{5}\right)-\dot{x}_{6}^{*}
$$

Setting the sliding surface $\dot{S}_{i d}=0$, one obtains the equivalent control law as:

$$
v_{d, e q}=\frac{2}{x_{4}}\left(R_{g} x_{6}-\omega_{s} L_{g} x_{5}\right)+\frac{2 L_{g}}{x_{4}} \dot{x}_{6}^{*}
$$

In order to get the discrete control law, the chosen Lyapunov function is defined as $W_{4}=\frac{1}{2} S_{i d}^{2}$. Using (34), the dynamics of the Lyapunov candidate are expressed as:

$$
\dot{W}_{4}=S_{i d}\left(\frac{1}{L_{g}}\left(\frac{x_{4}}{2} v_{d}-R_{g} x_{6}+\omega_{s} L_{g} x_{5}\right)-\dot{x}_{6}^{*}\right)
$$

It can easily be checked that the discrete control law $v_{d, n}=\frac{-2 L_{g}}{x_{4}} k_{i d} \operatorname{sgn}\left(S_{i d}\right)$ guarantees the negativity of $\dot{W}_{4}$, where $k_{i d}$ is the controller parameter.

Therefore, the global control law for d-axis control loop is written as:

$$
v_{d}=\frac{2}{x_{4}}\left(R_{g} x_{6}-\omega_{s} L_{g} x_{5}\right)+\frac{2 L_{g}}{x_{4}}\left(\dot{x}_{6}^{*}-k_{i d} \operatorname{sgn}\left(S_{i d}\right)\right)
$$

Remark: The chattering phenomenon can occur by using the signum function sgn(.). In this paper, we suggest modifying the control laws by means of using a sigmoid $\tanh ($.) function instead of $\operatorname{sgn}($.$) in order to avoid$ bringing in the vibration and nonlinearity into control signals during the reaching mode.

\section{HIGH GAIN OBSERVER}

In this section, a mechanical observer is employed to get online estimation of the mechanical torque and the generator speed so as to decrease the number of sensors that reduce the reliability of the system. Since the DFIG's dynamic behavior belongs to a class of relatively fast systems, the high gain observer is among the most suitable choices in the problem of state estimation. This choice is motivated by the fact that the observer structure involves an explicit correction gain [23]. To this end, a high gain state observer will be designed. Due to the fact that the position of the rotor is considered to be unknown because it needs a mechanical sensor, the $\mathrm{d}-\mathrm{q}$ frame cannot take place as it needs the rotor position information. Thus, the compact form of the DFIG model in the $\alpha$ - $\beta$ reference frame, is constructed as in (38) and (39).

$$
\begin{gathered}
\dot{w}=A w+g(w, i, u)+\delta(t) \\
y=C w=w_{1}
\end{gathered}
$$

where $w=\left(\begin{array}{lll}w_{1} & w_{2} & w_{3}\end{array}\right)^{T}=\left(\begin{array}{lll}T_{e m} & \Omega_{m} & T_{G}\end{array}\right)^{T}$ is the state space vector, $y$ is the output vector,

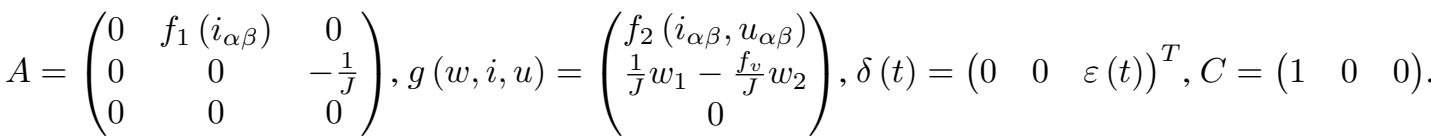

with $w_{1}=(3 / 4) p L_{m} i_{\alpha \beta}^{T} T_{0} i_{\alpha \beta}, \quad i_{\alpha \beta}=\left(\begin{array}{lllll}i_{s \alpha} & i_{s \beta} & i_{r \alpha} & i_{r \beta}\end{array}\right)^{T}, \quad u_{\alpha \beta}=\left(\begin{array}{llll}u_{s \alpha} & u_{s \beta} & u_{r \alpha} & u_{r \beta}\end{array}\right)^{T}$,

$f_{1}\left(i_{\alpha \beta}\right)=\left(3 p^{2} L_{m}\right) /\left(2 \sigma L_{s} L_{r}\right) i_{\alpha \beta}^{T} T_{0} F_{1} i_{\alpha \beta}, \quad f_{2}\left(i_{\alpha \beta}, u_{\alpha \beta}\right)=\left(3 p L_{m}\right) /\left(2 \sigma L_{s} L_{r}\right) i_{\alpha \beta}^{T} T_{0}\left(F_{2} u_{\alpha \beta}+F_{3} i_{\alpha \beta}\right)$,

$F_{1}=\left(\begin{array}{cc}-L_{m}^{2} J_{2} & -L_{r} L_{m} J_{2} \\ L_{s} L_{m} J_{2} & L_{s} L_{r} J_{2}\end{array}\right), F_{2}=\left(\begin{array}{cc}L_{r} I_{2} & L_{m} I_{2} \\ -L_{m} I_{2} & L_{s} I_{2}\end{array}\right), F_{3}=\left(\begin{array}{cc}-R_{s} L_{r} I_{2} & R_{r} L_{m} I_{2} \\ R_{s} L_{m} I_{2} & -R_{r} L_{s} I_{2}\end{array}\right)$, 
$T_{0}=\left(\begin{array}{cc}O_{2} & J_{2} \\ -J_{2} & O_{2}\end{array}\right), I_{2}=\left(\begin{array}{cc}1 & 0 \\ 0 & 1\end{array}\right), J_{2}=\left(\begin{array}{cc}0 & -1 \\ 1 & 0\end{array}\right), O_{2}=\left(\begin{array}{ll}0 & 0 \\ 0 & 0\end{array}\right)$.

And $\varepsilon(t)$ is a bounded function. Then, the state observer of systems (33) is designed as follows [24]:

$$
\dot{\hat{w}}=A \hat{w}+g(\hat{w}, i, u)-\Gamma^{-1}(i) \Delta_{\theta}^{-1} K C(\hat{w}-w)
$$

where $\Gamma(i)=\operatorname{diag}\left(1 \quad f_{1}\left(i_{\alpha \beta}\right) \quad-\frac{1}{J} f_{1}\left(i_{\alpha \beta}\right)\right)$ and $\Delta_{\theta}=\operatorname{diag}\left(1 \quad \frac{1}{\theta} \quad \frac{1}{\theta^{2}}\right), \theta$ is a constant positive gain. The gain matrix $\mathrm{K}$ is selected so that the matrix $(\bar{A}-K C)$ is Hurwitz, with $\bar{A}=\Gamma^{-1} A \Gamma$, which implies that $P(\bar{A}-K C)+(\bar{A}-K C)^{T} P=-I_{3}, P \in \mathbb{R}^{3}$.

The high gain observer stability can be proved using the Lyapunov stability theorem and by considering the quadratic Lyapunov function candidate: $W_{0}=\varepsilon^{T} P \varepsilon$, where $\varepsilon=\Gamma(i) \Delta_{\theta} \tilde{w}$ and $\tilde{w}=\hat{w}-w$ [24].

\section{SIMULATION RESULTS}

The focus in this work is made on the design of an output feedback controller that is carried out using the nonlinear model of the entire wind energy conversion chain adopted. The proposed controller is developed based on the sliding mode technique and using a high gain observer. This latter is employed to estimate the generator speed and the mechanical torque, which improve the WECS performance and reliability via eliminating the mechanical sensors. In this study, we are interested in the control of the back-to-back converter, i.e., RSC and GSC, taking into account the IGBT switching devices which are considered ideal in several works. In addition, our main concern in this paper is directed to both RSC and GSC making our study complete in comparison to other works that focus only on one of the two converters. Actually, the power transfer through the back-to-back converter can affect and disturb the global power injected into the utility grid. The model of the 2-MW DFIG-based WECS connected to the electrical network, employing the proposed output-feedback controller which was discussed in the previous sections and described by Figure 2 is performed using MATLAB/SIMULINK/SimPowerSystems environment.

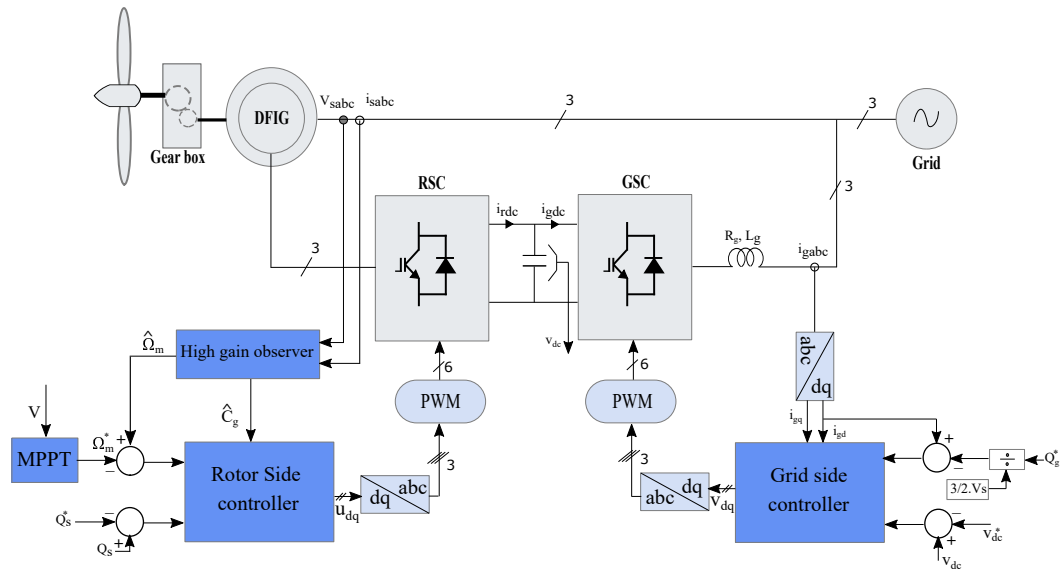

Figure 2. Schematic representation of the proposed wind energy conversion system with the controller design

The system parameters are given as follows:

Wind turbine parameters: $N=100, R=42 \mathrm{~m}, \rho=1.1225 \mathrm{Kg} \cdot \mathrm{m}^{3}$. DFIG and filter parameters: $V_{n} / U_{n}=$ $400 / 690 \mathrm{~V}, f=50 \mathrm{~Hz}, P_{n}=2 \mathrm{MW}, R_{s} / R_{r}=2.6 \mathrm{~m} \Omega / 2.9 \mathrm{~m} \Omega, L_{s} / L_{r}=2.6 \mathrm{mH} / 2.6 \mathrm{mH}, L_{m}=2.5 \mathrm{mH}$, $R_{g}=0.02 \mathrm{~m} \Omega, L_{g}=0.4 \mathrm{mH}, C=80 \mathrm{mF}$. Observer and controller parameters: $K=[25,8,33]^{T}, \theta=90$, $k_{\omega}=250, k_{Q}=300, k_{v}=120, k_{i d}=150, \delta_{1}=100, \delta_{2}=100$.

To demonstrate the validity of the output feedback controller, simulation results are obtained in the presence of a realistic wind speed profile with an average wind speed of $9 \mathrm{~m} / \mathrm{s}$ characterized by a $4 \%$ turbulence intensity over the time interval $\left[\begin{array}{lll}0 & 100 \mathrm{~s}\end{array}\right]$, as shown in Figure 3 (a), to further prove the efficiency of the proposed controller. Figures 3 (b)-(c), illustrate the generator speed and the mechanical torque of the DFIG and highlight the output feedback control loop convergence. Particularly, Figure 3 (b) shows the time-variations of the generator speed reference delivered by the MPPT block, together with the measured generator speed and its 
estimated value. As it can be noticed, the estimated value first matches the measured generator speed and both track the reference effectively so as to meet the control objectives. Also, Figure 3 (c) displays that the mechanical torque value provided by the high gain observer meets the measured mechanical torque which demonstrates the efficiency of the mechanical observer. Figure 3 (d) proves that the stator reactive power converges to the suggested reference which implies that only the active power is exchanged with the grid on the stator-grid connection. This keeps the currents sinusoidal and in opposite phase with the grid voltages, as shown in Figure 3 (g), complying with the PFC requirements. Figure 3 (e) verifies that the DC-link voltage is maintained at its recommended level, which guarantees the appropriate operation of the converter on the grid side. Figure 3 (f) shows the convergence of the grid side d-axis current which ensures that the reactive power exchanged with the electrical network on the rotor-grid connection is zero, thus proving the achievement of the GSC objectives. Figure 3 (g) represents one phase of the network voltage and current. The latter depends on the variation of the generated active power which fluctuates according to the wind velocity. Figure 3 (h) illustrates the mechanical power extracted by the wind turbine blades and the electrical power exchanged with the utility grid.

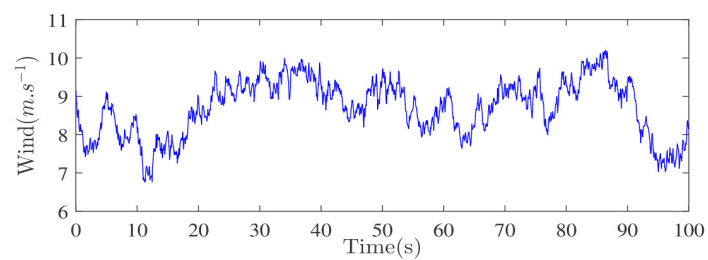

(a)

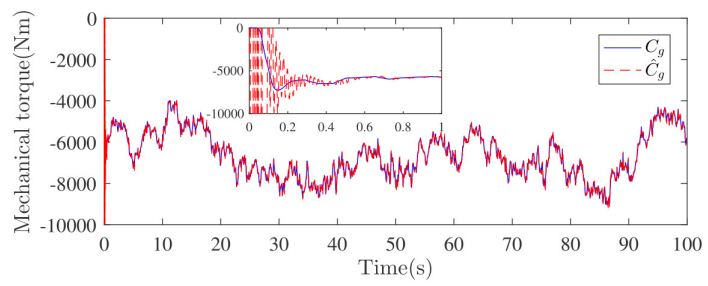

(c)

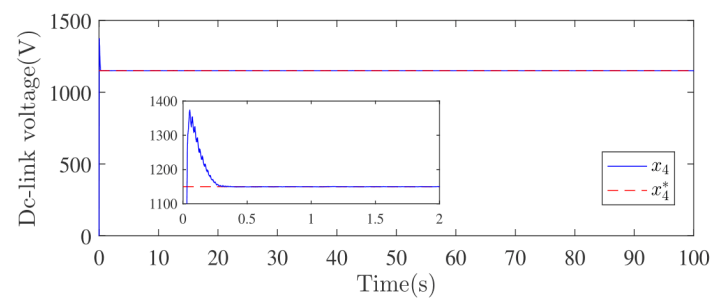

(e)

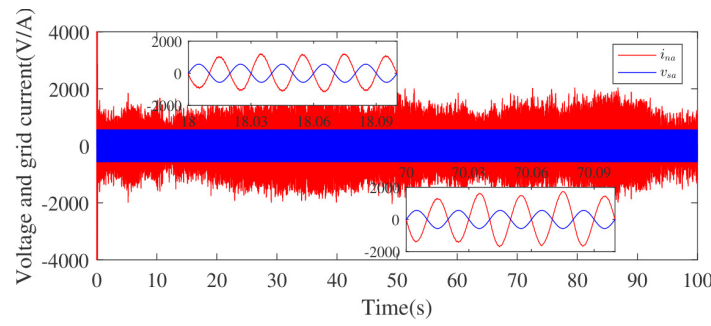

(g)

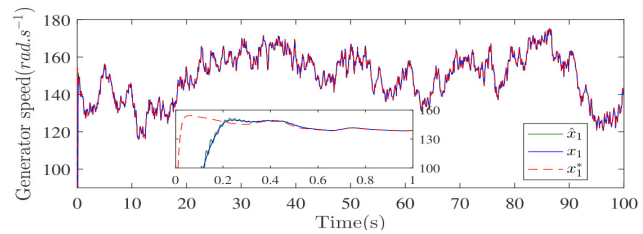

(b)

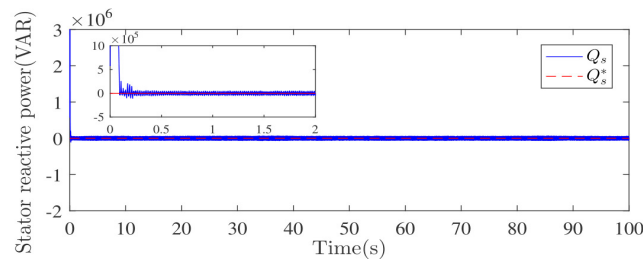

(d)

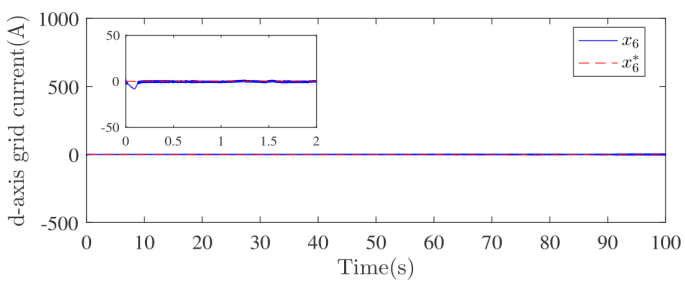

(f)

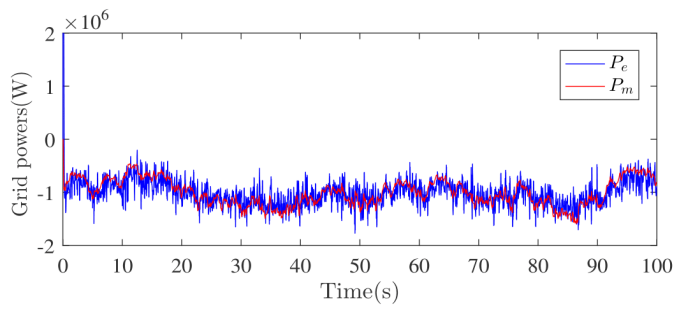

(h)

Figure 3. Wind energy conversion system estimation and convergence

The observer is synthesized using the DFIG model in the stationary reference frame ( $\alpha$ - $\beta$ frame) where the rotor position is not used for the observer modelling and implementation in order to increase the reliability of the system. The estimated value of the generator speed and mechanical torque are used as inputs 
of the sliding mode controller that aims at improving the performance of the conversion chain so as to meet the control objectives. The used controller ensures the system to converge faster than other regulators [7], [8], [10]. In addition, it allows the system to work without the presence of sensors, minimizing the cost and complexity of the overall structure, unlike other works that must lean on the signals provided by the sensors to achieve their control objectives [15], [25]. Another added-value of the present study relies on extracting the maximum available power given by the wind turbine blades. It is worth mentioning that the reactive power ripples shown in Figure 3 (d) according to the proposed design are much smaller than those shown in [10], [16]. In fact, the ripples in active and reactive powers have an influence on the current injected into the electrical grid and on the stress on the turbine shaft. This can lead to the destruction of the wind turbine.

\section{CONCLUSION}

In this article, a sliding mode controller is designed for the complete WECS constituted by a wind turbine connected to the grid via a DFIG and a back-to-back converter. The advantage of the proposed design is that it eliminates the requirement of mechanical sensors using a high gain observer, which improves the efficiency of the controlled system. It has been illustrated by a numerical simulation that the performance of the WECS based on the sensorless-sliding mode controller, under realistic wind profile, is better compared to other controllers and it can be concluded that the control objectives are efficiently achieved. We look forward to continuing this study in our next papers, first, by developing a novel MPPT strategy to improve the power extraction without the need of using an anemometer sensor for wind speed measurement, and then, by testing the control laws in real-time simulations in order to validate the system's performance.

\section{REFERENCES}

[1] N. Goudarzi and W. D. Zhu, "A review on the development of wind turbine generators across the world," International Journal of Dynamics and Control, vol. 1, no. 2, Jun. 2013, DOI: 10.1007/s40435-013-0016-y.

[2] B. Wu, Y. Lang, N. Zargari, and S. Kouro, "Power conversion and control of wind energy systems," John Wiley \& Sons, vol. 76, 2011.

[3] V. Meenakshi and S. Paramasivam, "Control Strategy Used in DFIG and PMSG Based Wind Turbines an Overview," International Journal of Power Electronics and Drive System (IJPEDS), vol. 8, no. 3, pp. 1160, Sept. 2017, DOI: 10.11591/ijpeds.v8.i3.pp1160-1167.

[4] M. Arif Sharafat Ali, "Utilizing Active Rotor-Current References for Smooth Grid Connection of a DFIG-Based Wind-Power System," Advances in Electrical and Computer Engineering, vol. 20, no. 4, pp. 91-99, Dec. 2020, DOI: 10.4316/AECE.2020.04011.

[5] K. Noussi, A. Abouloifa, H. Katir, and I. Lachkar, "Nonlinear Control of Active and Reactive Power in Grid-tied DFIG-WECS," ICEIT, pp. 1-6, Mar. 2020, DOI: 10.1109/ICEIT48248.2020.9113185.

[6] S. Kail, A. Bekri, and A. Hazzab, "Study of automatic generation control in two area power system with DFIG-based wind energy conversion," International Journal of Power Electronics and Drive System (IJPEDS), vol. 10, no. 4, pp. 2118-2125, Dec. 2019, DOI: 10.11591/ijpeds.v10.i4.pp2118-2125.

[7] B. Bensahila, A. Allali, H. Merabet Boulouiha, and M. Denai, "Modeling, Simulation and Control of a Doubly-Fed Induction Generator for Wind Energy, Conversion Systems," International Journal of Power Electronics and Drive Systems, vol. 10, no. 3, pp. 1197-1210, 2020, DOI: 10.11591/ijpeds.v11.i3.pp1197-1210.

[8] Z. Nora and L. Hocine, "Active and Reactive Power Control of a Doubly Fed Induction Generator," International Journal of Power Electronics and Drive Systems, vol. 5, no. 2, pp. 244-251, Oct. 2014, DOI: 10.11591/ijpeds.v5i2.6477.

[9] F. Mazouz, S. Belkacem, I. Colak, S. Drid, and Y. Harbouche, "Adaptive direct power control for double fed induction generator used in wind turbine," International Journal of Electrical Power\&Energy Systems, vol. 114, Jan. 2020, DOI: 10.1016/j.ijepes.2019.105395.

[10] K. Boureguig, A. Mansouri, and A. Chouya, "Performance enhancements of DFIG wind turbine using fuzzy-feedback linearization controller augmented by high-gain observer," International Journal of Power Electronics and Drive Systems, vol. 11, no. 1, pp. 10-23, Mar. 2020, DOI: 10.11591/ijpeds.v11.i1.pp10-23.

[11] M. Nadour, A. Essadki, and T. Nasser, "Coordinated control using backstepping of DFIG-based wind turbine for frequency regulation in high wind energy penetrated system," Mathematical Problems in Engineering, 2020, DOI: $10.1155 / 2020 / 8287949$.

[12] Q.V. Ngo, Y. Chai, and T.T. Nguyen, "The maximum power point tracking based-control system for small-scale wind turbine using fuzzy logic," International Journal of Electrical and Computer Engineering (IJECE), vol. 10, no. 4, pp. 3927-3935, Aug. 2020, DOI: 10.11591/ijece.v10i4.pp3927-3935.

[13] G. Rigatos and P. Siano, "DFIG control using differential flatness theory and extended Kalman filtering," IFAC 
Proceedings Volumes, vol. 14, no. 6, pp. 1763-1770, May 2012, DOI: 10.3182/20120523-3-RO-2023.00015.

[14] M. Morawiec, K. Blecharz, and A. Lewicki, "Sensorless Rotor Position Estimation of Doubly Fed Induction Generator Based on Backstepping Technique," IEEE Transactions on Industrial Electronics, vol. 67, no. 7, pp. 5889-5899, Jul. 2020, DOI: 10.1109/TIE.2019.2955403.

[15] B. Yang, T. Yu, H. Shu, J. Dong, and L. Jiang, "Robust sliding-mode control of wind energy conversion systems for optimal power extraction via nonlinear perturbation observers," Applied Energy, vol. 210, pp. 711-723, Jan. 2018, DOI: 10.1016/j.apenergy.2017.08.027.

[16] K. Noussi, A. Abouloifa, H. Katir, and I. Lachkar, "Modeling and Control of a Wind Turbine Based On a Doubly Fed Induction Generator," WCCS, pp. 1-5, Apr. 2019, DOI: 10.1109/ICoCS.2019.8930738.

[17] H. S. Ko, G. G. Yoon, N. H. Kyung, and W. P. Hong, "Modeling and control of DFIG-based variablespeed wind-turbine," Electric Power Systems Research, vol. 78, no. 11, pp. 1841-1849, Nov. 2008, DOI: 10.1016/j.epsr.2008.02.018.

[18] I. Yasmine and B. B. El Bekkali Chakib, "Power control of DFIG-generators for wind turbines variable-speed," International Journal of Power Electronics and Drive Systems, vol. 8, no. 1, pp. 444-453, Jan. 2017, DOI: 10.11591/ijpeds.v8.i1.pp444-453.

[19] J.J.E. Slotine and W. Li, ”Applied nonlinear control,” Englewood Cliffs, NJ: Prentice hall, vol. 199, no. 1, 1991.

[20] A.T. Azar and Q. eds. Zhu, "Advances and applications in sliding mode control systems," Cham, Switzerland: Springer International Publishing, 2015.

[21] A. Merabet, H. Eshaft, and A. A. Tanvir, "Power-current controller based sliding mode control for DFIG-wind energy conversion system," IET Renewable Power Generation, vol. 12, no. 10, pp. 1155-1163, Jul. 2018, DOI: 10.1049/ietrpg.2017.0313.

[22] M.E.B. Aguilar, D.V. Coury, R. Reginatto, and R.M. Monaro, "Multi-objective PSO applied to PI control of DFIG wind turbine under electrical fault conditions," Electric Power Systems Research, vol. 180, pp. 106081, Mar. 2020, DOI:10.1016/j.epsr.2019.106081

[23] B. Abdelhak and B. Bachir, "A high gain observer based sensorless nonlinear control of induction machine," International Journal of Power Electronics and Drive Systems (IJPEDS), vol. 5, no. 3, Feb. 2015, pp. 305-314, Feb. 2015, DOI: 10.11591/ijpeds.v6i1.6792.

[24] H. K. Khalil, "High-gain observers in nonlinear feedback control," 2008 International Conference on Control, Automation and Systems, Oct. 2008, DOI: 10.1109/ICCAS.2008.4694705.

[25] F. Golnary and H. Moradi "Dynamic modelling and design of various robust sliding mode controls for the wind turbine with estimation of wind speed," Applied Mathematical Modelling, vol. 65, pp. 566-585, Jan. 2019, DOI: 10.1016/j.apm.2018.08.030.

\section{BIOGRAPHIES OF AUTHORS}

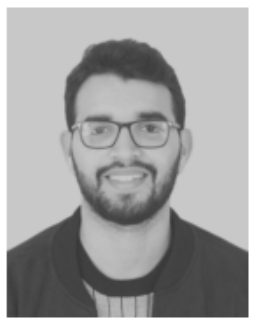

Karim Noussi received his Master's degree in information processing in 2017 from the Faculty of Science Ben M'sick, Hassan II University. Since 2017, he has been preparing his Ph.D. in the field of automatic, renewable energy and electrical machines at University Hassan II, Casablanca, Morocco. The main topics of his research are in the field of robust and advanced control methods of AC drives associated with power electronic converters for wind power generation.

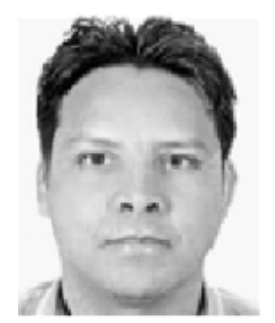

Abdelmajid Abouloifa received the Aggregation of Electrical Engineering from Normal High School, Rabat, Morocco, in 1999, and Ph.D. degree in control engineering from the University of Caen Basse-Normandie, Caen, France and from Mohammed V University, Rabat, Morocco in 2008. $\mathrm{He}$ is currently Professor at the Faculty of Sciences Ben M'sick, University Hassan II, Casablanca, Morocco. His research interests include high frequency power converter topologies, power-factorcorrection techniques, power supplies, and nonlinear control. 


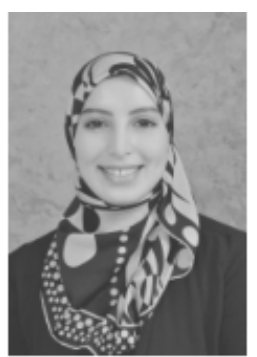

Hanane Katir received her Master's degree in information processing from the Faculty of Sciences Ben M'Sick, University Hassan II, Casablanca, Morocco, in 2017. Since 2017, she has been preparing her Ph.D. in the field of automatic, renewable energies and multilevel converters in the Faculty of Sciences Ben M'sick, University Hassan II, Casablanca, Morocco. Her research interests include the nonlinear control of Cascaded H-Bridge Multilevel Converters, Grid-connected systems, Uninterruptable Power Supplies, and renewable energies.

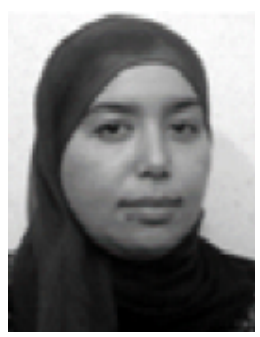

Ibtissam Lachkar received the graduate degree from the Normal High School of Technical Education, Rabat, Morocco, in 1995 and her degree of high depth studies from the Mohammedia School of Engineers, Rabat, in 2005. She received her Ph.D. from Mohammedia School of Engineers. Currently, she is an Assistant Professor at National School of Electricity and Mechanic.

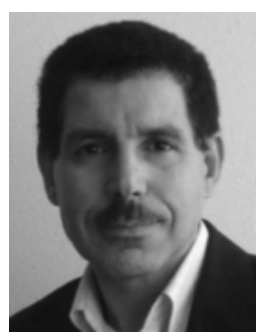

Fouad Giri received his $\mathrm{PhD}$ in automatic control from the Institute National Polytechnique of Grenoble, France, in 1988. He is Professor at the University of Caen basse-Normandie, Caen, France. His research interests include nonlinear system identification, nonlinear, adaptive and constrained control, and the application of identification and control theory to power converters and electric machines. 